\title{
SCHMITT, REPRESENTAÇÃO E FORMA POLÍTICA
}

BERNARDO FERREIRA

Publicado em 1923, o livro Römischer Katholizismus und poli tische Form (Catolicismo romano e forma política) até recentemente não ocupava um lugar de destaque entre os textos de Carl Schmitt ${ }^{1}$ dos anos da República de Weimar. O próprio tema do livro e, em particular, o tom com que ele é tratado, certamente contribuíram para essa desatenção. Estamos diante de uma discussão sobre a natureza jurídica da Igreja que não esconde o seu teor apologético e provocativo, quando não calculadamente antimoderno, o que parece restringir o seu interesse a uma espécie de curiosidade, sem maior importância teórica, no quadro geral da produção de Schmitt no período em questão. Um testemunho, talvez, das suas convicções pessoais e do seu envolvimento com os círculos intelectuais do conservadorismo católico. Todavia, nos últimos tempos, o livro se tornou objeto de uma atenção mais cuidadosa: ele tem sido valorizado como uma

\footnotetext{
${ }^{1}$ Legenda para os textos de Carl Schmitt citados:

Der Begriff des Politischen. Berlin, Duncker \& Humblot, 1996, $6^{\text {a }}$ ed. (reimpressão da $2^{\text {a }}$ ed. de 1932) - BP

Die Diktatur. Von den Anfängen des modernen Souveränitätsgedankens bis zum prole tarischen Klassenkampf. Berlin, Duncker \& Humblot, 1994, $6^{\text {a }}$ ed. (reimpressão da $2^{\mathrm{a}}$ ed. de 1928) - D

Der Hüter der Verfassung. Berlin, Duncker \& Humblot, 1996, 4ª ed. (1 ${ }^{\text {a }}$ ed. 1931) - HV

Politische Theologie. Berlin, Duncker \& Humblot, 1996, $7^{\mathrm{a}}$ ed. (reimpressão da $2^{\mathrm{a}}$ ed. de 1934) - PT

Positionen und Begriffe. Berlin, Duncker \& Humblot, 1988, $2^{\mathrm{a}}$ ed. (1ª ed. 1940) - PuB

Römischer Katholizismus und politische Form. Stuttgart, Klett-Cotta, 1985 (reimpressão da $2^{\mathrm{a}}$ ed. de 1925) - RK

"Staatsethik und pluralistischer Staat" (texto de 1930, posteriormente republicado em Positionen und Begriffe) - SpS

Verfassungslehre. Berlin, Duncker \& Humblot, 1989, $7^{\mathrm{a}}$ ed. (1 $1^{\mathrm{a}}$ ed. 1928) - VL

Der Leviathan in der Staatslehre des Thomas Hobbes. Stuttgart, Klett Cotta, 1982 (1 $1^{\mathrm{a} e d .}$ 1938) - LSTH
} 
obra central na produção de Schmitt dos anos 20 e sua importância para uma compreensão mais matizada e complexa das suas idéias vem sendo ressaltada. Nessa perspectiva, acredito que a discussão desse texto permite enquadrar as idéias políticas de Carl Schmitt no contexto da sua crítica da modernidade e fornece elementos para uma abordagem mais precisa sobre o lugar que problemas como soberania, decisão e "político" ocupam no seu pensamento.

Como tantos outros trabalhos que Schmitt escreveu nos anos 20, Römischer Katholizismus und politische Form é enganadoramente breve nas suas dimensões, quase um folheto, e se constrói a partir de uma série de contraposições: entre catolicismo e modernidade, política e economia, racionalidade jurídica e racionalidade técnica. Para Schmitt, em um mundo crescentemente dominado pela lógica instrumental da técnica moderna, a Igreja Católica seria a verdadeira portadora de um princípio de forma jurídica e de uma idéia política. A seu ver, isso ocorreria sobretudo porque a Igreja seria a mais acabada expressão de uma complexio oppositorum. Ao contrário da experiência moderna da realidade, na qual, segundo ele, um "dualismo radical domina efetivamente em todas as esferas" (RK, 16), no catolicismo, os contrários se encontrariam reunidos em uma espécie de unidade capaz de abarcar (Schmitt usa o verbo umfassem) as mais diferentes oposições, sem reduzí-las, no entanto, a uma síntese qualquer². O que distinguiria a complexio católica seria, antes de tudo, a sua capacidade de "formação [formierung]" (RK, 24) da realidade. Assim, observa Schmitt,

considerada do ponto de vista da idéia política do catolicismo, a essência da complexio oppositorum romano-católica reside em uma superioridade especificamente formal sobre a matéria da vida humana, como nenhum Império até hoje conheceu. Aqui se alcança uma configuração substancial [substantielle Gestaltung] da realidade histórica e social, que, a despeito do seu caráter formal, se mantém na existência concreta, plena de vida, e, no entanto, é racional na mais alta medida. $(\mathrm{RK}, 14)$

Esse trecho como que condensa um conjunto de idéias que está no centro da reflexão de Schmitt sobre o catolicismo romano. Ao mesmo tempo, é possível reconhecer aqui uma figura de fundo em contraposição à

2 Segundo ele,"parece não haver contraposição que ela [a Igreja católica] não abarque [umfasst]"(RK, 11). 
qual ganha um desenho próprio a imagem da complexio católica. Schmitt, com efeito, elabora a sua defesa da Igreja católica tendo como referência negativa a idéia de um racionalismo característico do que ele chama de "pensamento técnico-econômico". Prestemos mais atenção a esse ponto.

Schmitt considera a Igreja católica de uma perspectiva que, na falta de palavra mais adequada, poderia ser caracterizada como fundamentalmente mundana. A imagem que emerge dessa análise do catolicismo está dirigida acima de tudo para sua força político-jurídica. A Igreja católica se distinguiria por uma racionalidade própria. "Esse racionalismo", nos diz ele, "reside no institucional e é essencialmente jurídico" (RK, 23). Trata-se de uma capacidade de conformação da realidade humana que, ao contrário do racionalismo técnico, não se traduz em simples "domínio e utilização da matéria" (RK, 23). A complexio católica é concebida aqui em evidente oposição à natureza instrumental do "pensamento técnico-econômico". Mas não só. Se é verdade que a imagem de uma racionalidade característica do catolicismo é pensada como a contrapartida de um modelo de razão consagrado pelo desenvolvimento técnico-científico, por outro lado, ela também se contrapõe, na análise de Schmitt, à dinâmica da própria modernidade, que nos é apresentada, significativamente, como a "época do pensamento econômico" (RK, 35). Mas, enfim, pode-se perguntar, o que diferencia o racionalismo moderno do seu contramodelo católico?

Em primeiro lugar, a Igreja católica, segundo Schmitt, não pode ser pensada no horizonte do "dualismo estrutural" da época moderna. $\mathrm{O}$ racionalismo católico não se nutriria da fratura entre espírito e natureza, pensamento e ser, sujeito e objeto que seria característica da instrumentalização da realidade pelo racionalismo técnico-econômico. A "potência [Macht] do catolicismo" (RK, 8) seria o resultado da sua capacidade de moldar a matéria viva da experiência, sem reduzi-la a esquemas abstratos. Esse movimento de dar forma à experiência se contrapõe, no argumento de Schmitt, à crença moderna na possibilidade de subjugação racional da realidade. Ao pensar o mundo como o seu outro, o racionalismo técnicocientífico o esvaziaria de sentido, tornando-o objeto de um projeto de dominação que reproduz insistentemente as dissociações dualistas, sem lhes oferecer, entretanto, uma direção própria.

Nessa perspectiva, Schmitt se permite contrapor, em uma clara referência a Max Weber, o terrisme $(\mathrm{RK}, 18)$ dos povos católicos ao desenraizamento da ascese intramundana dos protestantes. O vínculo com a terra se apresenta aqui como a metáfora de uma atitude para a qual não faz sentido a antítese entre natureza e ratio (cf. RK, 18). Ao mesmo tempo, não 
é difícil reconhecer nessa oposição entre catolicismo e protestantismo uma tentativa de afirmar a "paternidade" católica da política moderna, em contraposição à imagem, consagrada por Weber, de uma "ascendência" protestante da economia. No entanto, mais significativa, a meu ver, do que essa pretensão é a idéia de que o catolicismo representa a fonte de um tipo de racionalidade que não só se diferencia da versão técnico-científica moderna, mas também seria capaz de se opor à dominação inconteste dessa última. ${ }^{3}$ A peculiaridade da racionalidade jurídica do catolicismo estaria em uma "maneira de pensar interessada na condução normativa da vida social dos homens" (RK, 21). Dessa forma, a oposição que Schmitt estabelece entre os pares economia-técnica e política-direito diz respeito, antes de tudo, à possibilidade de algum tipo de condução e governo da realidade humana. Para ele, o racionalismo técnico-econômico no seu projeto de domínio e utilização do real seria presa de uma inevitável deriva, fruto da incessante reprodução das suas próprias premissas dualistas, revelando-se incapaz de estabelecer a partir delas qualquer tipo de unidade. À racionalidade característica do pensamento econômico, observa Schmitt, "lhe falta o todo [das Alles]" (RK, 37). A seus olhos, portanto, o racionalismo católico não pode meramente ser "o pólo com alma da ausência de alma [die seelenvolle Polarität der Seelenlosigkleit]" (RK, 19), mas sim uma maneira de pensar que permita superar esse tipo de polaridade e deter aquela deriva. Por isso, o catolicismo possui uma "força criadora racional" própria que

dá uma direção à escuridão irracional da alma humana, sem levá-la à força até a luz. Ela não dá, como o racionalismo técnicoeconômico, receitas para a manipulação da matéria. (RK, 24)

Na interpretação de Schmitt sobre o catolicismo, a técnica é analisada como fruto de uma crescente racionalização dos meios em detrimento da racionalidade dos fins. Como ele próprio observa, para o pensamento técnico-econômico,

\footnotetext{
${ }^{3}$ Nessa perspectiva, Catherine Colliot-Thélene afirma que, a despeito dos seus pontos de convergência, Schmitt mantém uma relação marcadamente polêmica com Max Weber. Mais do que uma réplica do católico ao protestante, a análise de Schmitt em RK seria uma "réplica do político ao economista" (COLLIOT-THÉLÈNE, Catherine - Carl Schmitt contre Max Weber: rationalité juridique e rationalité economique in HERRERA, Carlos-Miguel (org.) - Le droit, le politique. Autour de Max Weber, Hans Kelsen, Carl Schmitt, Paris, L’Harmattan, 1995, p. 211). Segundo ela, "a obra weberiana se apresenta, aos olhos de Schmitt, como uma expressão emblemática da hegemonia adquirida pelo "pensamento econômico"” (ibid., p. 215).
} 
denomina-se "racional" um mecanismo de produção que serve a qualquer necessidade material, sem que se pergunte pela única racionalidade essencial, a racionalidade do fim [der allein wesentlichen Rationalität des Zweckes] para o qual o mecanismo sumamente racional está disponível. (RK, 26)

Essa caracterização da racionalidade da técnica moderna é de central importância na discussão de Schmitt sobre a especificidade do racionalismo da Igreja católica e, portanto, sobre a natureza da forma político-jurídica. $\mathrm{O}$ desconhecimento do problema dos fins característico do desenvolvimento técnico-científico acabaria por conduzir a uma concepção de racionalidade despojada de todo conteúdo e centrada nos princípios do cálculo, da eficiência e da previsibilidade, uma racionalidade, enfim, que "só conhece um tipo de forma, ou seja, a precisão técnica" (RK, 34). A forma técnica, se apresenta acima de tudo como uma "forma vazia" (RK, 19). A sua "imperturbável objetividade [unbeirrte Sachlichkeit]" (RK, 22) pressupõe, em última análise, a eliminação de toda e qualquer definição normativa de caráter substantivo. Assim, a crítica de Schmitt à racionalidade instrumental, deriva menos do receio de uma sociedade administrada - problema que, diga-se de passagem, não é estranho à sua reflexão - do que de uma convicção de que semelhante racionalidade não é capaz de governar a vida social e de lhe conferir uma forma própria. Dessa maneira, o caráter instrumental e vazio da racionalidade econômica se opõe, na sua análise, à maneira de pensar normativa característica da complexio católica e ao conteúdo substantivo da forma jurídica.

Todavia, Schmitt não relaciona, como se poderia imaginar, essa dimensão normativa do catolicismo aos princípios morais da religião cristã. Estamos distantes de uma tentativa de restaurar algo semelhante a um direito natural cristão. O caráter normativo da "idéia política do catolicismo" tem como premissa uma racionalidade institucional, capaz de compreender e configurar na unidade das suas formas a natureza múltipla e contraditória da experiência concreta. É esse enraizamento no concreto que faz da forma jurídico-política, por definição, uma "forma substancial" (RK, 50).

Para Schmitt, o que distingue a orientação normativa da racionalidade católica é a sua capacidade de transcender o imediato da realidade e incorporá-la em uma ordem que pressupõe algum tipo de princípio de totalização. O pensamento técnico-econômico, em contrapartida, resultaria de um ponto de vista puramente imanente; trata-se de um pensamento 
que "se mantém absolutamente objetivo [sachlich], ou seja, nas coisas [bei den Dingen]" (RK, 27). Mas, afinal, em que consiste mais precisamente esse "permanecer nas coisas"? Creio que duas questões básicas estão envolvidas nessa idéia.

Em primeiro lugar, está em jogo nessa afirmação a imagem de que a Sachlichkeit (objetividade) do pensamento técnico-econômico é inseparável de uma perspectiva que reduz a realidade à sua mera Dinghaftigkeit (condição de coisa) ${ }^{4}$. A "objetividade absoluta" desse pensamento não se diferencia daquela que é própria de um objeto ou de uma coisa na sua muda materialidade. Trata-se de uma concepção da realidade, e em particular da realidade social, que a despoja de todo e qualquer significado e conteúdo próprios, transformando-a em um mero mecanismo. Como observa Catherine Colliot-Thélène, para Schmitt, a técnica e a economia moderna são solidárias da imagem da natureza e do conceito de verdade inaugurado pela ciência no século XVII ${ }^{5}$. Em ambos os casos a realidade se vê reduzida a um conjunto de processos mecânicos que, em tese, obedecem às suas próprias leis, desconhecem considerações normativas e não admitem intervenção do arbítrio humano. Esse último introduziria um dado de singularidade e contingência, sob todos os aspectos estranho a uma regularidade supostamente impessoal. Em última análise, para o pensamento técnico-econômico, observa Schmitt, "o político é nãoobjetivo [unsachlich]" (RK, 27). Como se fossem a expressão de uma necessidade natural, os processos da técnica e da economia seguiriam uma lógica autônoma, independente da vontade dos agentes sociais. Sendo assim, 'nem os homens, nem as coisas precisam de um 'governo', caso se deixe o mecanismo da esfera econômica e da esfera técnica entregue à sua legalidade [Gesetzmäßigkeit] imanente" (RK, 60). A contraface de uma imagem reificada da vida social estaria na afirmação de uma ordem imanente às próprias coisas. Nesse quadro, o problema da autoridade política e do governo dos homens sobre os homens se apresenta como "uma interferência na máquina que funciona por si mesma" (RK, 45). Para Schmitt, essa crença na possibilidade de derivar a ordem da sua dinâmica imanente implica conceber a atividade humana e a vida social de forma coisificada, reduzindo-a à sua dimensão exclusivamente material.

Ao pensar a atividade humana de forma coisificada, em função da sua mera Dinghaftigkeit, o pensamento técnico-econômico não se

${ }^{4}$ Para o uso da expressão Dinghaftigkeit, vide RK, 35.

${ }^{5}$ Cf. COLLIOT-THÉLÈNE, Catherine - op. cit., pp. 218-219. 
mostraria capaz de transcender a realidade na sua dimensão mais imediata, tornando-se presa daquilo que é efetiva e materialmente dado. Com isso, chegamos ao meu segundo ponto. $\mathrm{O}$ "permanecer nas coisas" característico do pensamento técnico-econômico envolve não só uma imagem reificada da realidade, mas também uma espécie de recusa a conceber algo que esteja para além do mundo das coisas. Ele implicaria assumir o ponto de vista da plena imanência e renunciar a toda compreensão da vida social que não partisse de seu aqui-e-agora empírico. De fato, observa Schmitt, tal pensamento "exige uma presença real das coisas [Realpräsenz der Dinge]" (RK, 35). No entanto, seria justamente essa perspectiva, no que ela tem de materialista e, sobretudo, no seu apego à imanência, que lhe impediria de compreender o processo de "configuração de ordem e unidade", de que a com plexio católica seria exemplar. Tal processo envolveria uma "dimensão ideal" que, aos olhos de Schmitt, não está ao alcance de uma consideração imanente. A constituição da ordem política não se esgota na mera efetividade daquilo que existe como um dado empírico, ela exige tanto um movimento de justificação normativa quanto de configuração de uma unidade. Nesse sentido, observa Schmitt,

enquanto existe um resíduo de idéia, também domina a concepção de que diante da efetividade daquilo que é materialmente dado [gegebenen Wirklichkeit des Materiellen] há algo de preexistente, transcendente, e isso significa sempre uma autoridade de cima para baixo [von oben] $(\mathrm{RK}, 45)$.

Por sua "adesão" às coisas, escaparia ao pensamento técnicoeconômico esse elemento de transcendência que, segundo Schmitt, é inerente ao processo de constituição da unidade política. O caráter imanente desse pensamento reduziria a compreensão da realidade àquilo que já está dado na existência empírica. A técnica e a economia se apresentam, dessa forma, como produtos da orientação mundana e secular da modernidade. Tanto uma quanto a outra remetem a uma compreensão unidimensional da experiência social e política; compreensão essa que a reduz a um conjunto de processos regidos por uma lógica imanente e que a esgota no aqui-eagora de algo empiricamente presente. Assim, a antítese entre economiatécnica e política-direito está inserida em uma perspectiva mais ampla que afirma a impossibilidade de esgotar a experiência na sua dimensão imediata e material, de limitar a ordem a um conjunto de processos mecânicos e técnicos, de restringir a vida social a uma concepção objetivante e coisificada; 
uma perspectiva, enfim, que pretende contrapor à imanência da época moderna a necessidade de um elemento ideal e transcendente na constituição da unidade política.

A complexio católica se apresenta, na análise de Schmitt, como o exemplo mais acabado de uma ordem que encontra coerência e unidade em um princípio de totalização que está para além da realidade imediata. Um dos fatores que distingue a racionalidade da Igreja como "portadora do espírito jurídico" (RK, 31) seria a sua remissão a uma dimensão transcendente. A "força criadora racional" do catolicismo estaria no fato de que a sua organização institucional remonta à própria pessoa de Cristo (cf. RK, 24). Porém, já observei, Carl Schmitt interpreta essa estrutura transcendente da racionalidade católica do ponto de visto do seu significado jurídico, interessa-lhe "compreender o religioso juridicamente" (RK, 49). O catolicismo romano, como o próprio título do livro indica, constitui, a seu ver, um modelo de forma política. A Igreja, em virtude da sua "capacidade de forma" (RK, 38), possui um caráter exemplar e, justamente por isso, "pressupõe a seu lado o Estado político" (RK, 42).

Mas em que medida o catolicismo se apresenta como modelo para Schmitt? Parte da resposta já sabemos: a Igreja é portadora de uma racionalidade própria; uma racionalidade concreta, que, à diferença daquela dominante na modernidade, se revelaria capaz de dar forma e unidade aos elementos contraditórios da vida, sem pretender esgotá-los nas formas abstratas de um pensamento fechado em si mesmo. A racionalidade do catolicismo se apresenta, na análise de Schmitt, como o duplo invertido da compreensão econômica e técnico-cientifíca da realidade consagrada no mundo moderno. Ao contrário dessa última, não apresentaria um caráter dualista, mas revelaria um potencial unificador e totalizante; não se confundiria com as formas vazias da precisão e da calculabilidade, mas exibiria uma natureza normativa e substancial; não se esgotaria nos esquemas reificados de uma perspectiva imanente, mas possuiria uma estrutura transcendente.

O eixo dessas oposições se encontra, segundo Schmitt, na natureza representativa da Igreja. Para ele, a "peculiaridade formal do catolicismo romano reside na rigorosa realização do princípio da representação" (RK, 14). A Igreja, afirma ele, "representa" a própria pessoa de Cristo, através dela o fenômeno da encarnação se "atualiza" e o filho de Deus se mantém "presente" entre os homens. Schmitt, no entanto, se revela menos interessado na dimensão mística dessa presença - a Igreja como a comunidade dos fiéis batizados em Cristo e o seu Corpo Místico -, do que 
no seu caráter institucional. Para ele, semelhante presença ganharia concretude e visibilidade na estrutura institucional da Igreja, que não só remonta ao próprio Cristo, mas torna possível a sua "personificação" no exercício da função sacerdotal e, portanto, no interior de uma cadeia de ofícios. A Igreja realiza, nas palavras de Schmitt, "uma representação concreta, pessoal de uma personalidade concreta" (RK, 31). A peculiaridade formal e a força normativa da representação eclesiástica se evidenciariam no fato de que essa atualização da presença de Cristo na Igreja confere uma dignidade pessoal ao sacerdote, ao mesmo tempo que a desvincula da sua pessoa individual. Através da dissociação entre ofício e carisma, o que poderia haver de desmedido na irracionalidade da experiência religiosa ganha uma direção específica e é contido dentro dos limites de uma arquitetura institucional (cf. RK, 23-24). A força da "idéia política do catolicismo" estaria na sua capacidade de conformar a realidade humana a partir de um princípio de unificação que transcende essa mesma realidade e, ao mesmo tempo, se atualiza nela. Representação e "capacidade de forma" são, nessa perspectiva, as duas faces de uma mesma moeda. Se a Igreja é "portadora do espírito jurídico" e de uma racionalidade específica, isso se deve ao fato de que ela dá à vida social unidade e direção, conferindo-lhe uma ordem própria através da mediação de um princípio transcendente na experiência concreta. Sendo assim, para utilizar os termos de Hasso Hofmann, a Igreja se apresenta para Schmitt como um modelo do processo através do qual se realiza "a transformação de uma condição qualquer em uma condição jurídica" 6 . Esse processo pressupõe um movimento de configuração daquilo que existe a partir de algo que, por definição, não é um dado empírico. Em contraposição à lógica da imanência dominante no mundo moderno e à Dinghaftigkeit do pensamento técnico-econômico, a Igreja se apresenta como o exemplo por excelência de uma mediação entre ideal e real". Nesse sentido, acredita Schmitt, "a sua superioridade sobre uma época de pensamento econômico está na dimensão representativa [im Repräsentativen]” (RK, 32).

Creio que agora começam a ficar mais claras algumas das questões envolvidas na oposição que Schmitt estabelece entre política e economia, catolicismo e modernidade. Mesmo assim, vejamos esse ponto com mais vagar, considerando alguns aspectos do conceito-chave dessa

6 HOFMANN, H. - Legalità contro legitimità. Nápoles, ESI, 1999, p. 93.

7 Para essa idéia, ver, em particular, NICOLETTI, M. - Trascendenza e potere. Brescia, Morcelliana, 1990 (cap. VII) e DUSO, Giuseppe - La Rappresentanza: un Problema di Filosofia Politica, Milão, Franco Angeli, 1988 (cap. IV). 
discussão. Refiro-me, evidentemente, à idéia de Repräsentation ${ }^{8}$. Para tanto, a minha análise que, até aqui se restringiu ao livro sobre o catolicismo, incluirá também a sua Verfassungslehre (Teoria da Constituição), de 1928.

Em primeiro lugar, o conceito de representação proposto por Schmitt em Catolicismo Romano e Forma Política, e posteriormente retomado em Teoria da Constituição, é indissociável de uma dimensão ideal. Como ele próprio observa, não se trata de "um conceito com caráter de coisa [dinghafter Begriff]" (RK, 36). De fato, como disse há pouco, aquilo que se representa não é um dado da realidade imediata, mas sim algo que, por definição, a transcende. Por esse motivo, Schmitt pode afirmar que

Deus, ou o povo na ideologia democrática, ou idéias abstratas como liberdade e igualdade são conteúdos concebíveis de uma representação, mas não produção e consumo (RK, 36).

Esse elemento ideal envolvido no ato de representar se encontra, na análise de Schmitt, em evidente contraposição à imanência do pensamento técnico-econômico. Enquanto produção e consumo pressupõem "a presença real das coisas", a representação dá figura e forma a algo que não existe como um dado imediato. A unidade daí resultante não nasce das próprias coisas, mas da sua configuração unitária, a partir de uma instância ou um princípio transcendente, seja ele Deus ou, de um ponto de vista secular, uma idéia. A representação, aos olhos de Schmitt, implica um movimento de mediação entre esse princípio ideal, que excede a experiência empírica, e a realidade concreta. Sendo assim, a constituição de ordem e unidade através da atividade representativa contém em si um componente irreconciliável com uma perspectiva que reduza a realidade à sua dimensão imanente e imediata. Não se representa algo que já está presente, mas sim algo que vem a ser presentificado.

$\mathrm{O}$ "parentesco no plano da forma [Verwandtschaft im Formalen]" (RK, 50) que Schmitt acredita ser possível firmar entre a representação eclesiástica e a estatal reside no fato de que, em ambos os casos, a constituição de uma ordem e de uma unidade concretas, ou seja, de uma complexio oppositorum, remete a um princípio de totalização que não está dado no mundo das coisas. O Cristo que se faz presente na Igreja excede a realidade imediata, da mesma forma que "o 'todo' do povo [das "Ganze" de Volkes] é apenas uma idéia" (RK, 45). Representar a unidade

${ }^{8}$ Para o que se segue, o texto já citado de Giuseppe Duso constitui uma importante referência. 
do povo significa, portanto, conferir expressão concreta, visibilidade, forma a uma noção ideal e, em última análise, transcendente. Se é verdade, como pretende Schmitt, que a Igreja "pressupõe o Estado a seu lado", isso resulta do fato de que entre os dois seria possível reconhecer uma analogia estrutural baseada no princípio da representação 9 .

Ainsistência de Schmitt nesse elemento ideal e transcendente traz consigo uma série de desdobramentos para o seu conceito de representação. Com efeito, como procurei observar há pouco, o representar implica, para ele, um movimento de presentificação de algo que não está dado na experiência empírica. Nesse sentido, a representação política significa configurar aquilo que existe a partir de uma noção ideal que dessa maneira ganha figura e existência concreta. Na Teoria da Constituição, ele irá formular esse problema em termos da relação entre visível e invisível, presença e ausência:

representar significa tornar visível e presentificar [sichtbar machen und vergegenwärtigen] um ser invisível por meio de um ser publicamente presente [ein öffentlich anwesend Sein]. A dialética do conceito reside no fato de que o invisível é pressuposto como ausente [abwesend] e, todavia, ao mesmo tempo, tornado presente [anwesend] (VL, 209-210).

Para Schmitt, a unidade de um povo, a idéia de ordem política são representados na medida em que não constituem uma realidade previamente presente, assumindo, portanto, visibilidade e presença através da representação. Essa última, "ao dar forma ao "todo do povo", faz algo mais do que simplesmente colocar-se no seu lugar, em alguma medida "ela o cria". Por isso, Schmitt insiste na idéia de que a representação (Repräsentation) não se reduz a um mero "estar em lugar de" (Stellvertretung) (cf. RK, 36), não se confundindo com as noções de mandato e delegação. O representado, sob determinados aspectos, é um produto da própria representação e não alguma coisa que a antecede. Nesse sentido, a representação política se distingue da eclesiástica pelo fato de que o Cristo que se torna presente na Igreja não é, e não pode ser, criado

9 Existiriam, no entanto, diferenças de natureza ontológica entre a representação do divino na Igreja e a representação de uma idéia secular de ordem no Estado. Como o próprio Schmitt observa, o catolicismo "representa algo de diverso e maior em relação à jurisprudência mundana, ou seja, não apenas a idéia de justiça mas a pessoa de Cristo" (RK, 50). Não pretendo ignorar esse aspecto do problema, apenas estou mais interessado em sublinhar as semelhanças estruturais do que as diferenças ontológicas. 
pelo ato da representação ${ }^{10}$. A presentificação política, até certo ponto, remete a si mesma e não a um referente externo. Ainda que implique uma dimensão transcendente, esta não está dada fora da representação, mas é pressuposta e, em última análise, "posta" por ela, distinguindo-se, assim, da natureza substancial da transcendência divina.

O movimento de formação característico do ato de representar tem, portanto, uma dupla direção: ele se dirige a uma idéia abstrata e ausente, conferindo-lhe forma concreta e presença visível e, ao mesmo tempo, à "matéria da vida humana", que, dessa maneira, vem a ser formada e configurada ${ }^{11}$. Nesse sentido, observa Schmitt, a Igreja, "de maneira conseqüente, representa 'de cima para baixo' [von oben]” (RK, 43). A ação do representante não resulta de uma autorização ou de uma delegação, não se apresenta, portanto, como a expressão de uma vontade antecedente; a representação, enfim, não se confunde com o mandato. Nada mais característico dessa perspectiva do que as observações de Schmitt sobre o parlamento moderno. Segundo ele, enquanto foi capaz, por oposição ao monarca, de se apresentar como uma representação do conjunto da nação, o parlamento conservou um caráter representativo. Nesse quadro, os representantes teriam em relação ao eleitorado e aos interesses da vida social uma posição de independência. Com efeito, observa Schmitt,

o sentido elementar do princípio representativo reside no fato de que os deputados são representantes de todo o povo e, por isso, possuem uma dignidade independente em relação aos seus eleitores sem deixar de derivar essa dignidade do povo (e não dos eleitores individuais) (...) Isso significa, ao menos em tese, que, na personificação do povo e na unidade do parlamento como seu representante, se dá uma complexio oppositorum, ou seja, uma complexio da multiplicidade de partidos e interesses em uma unidade, que como tal é concebida de maneira representativa e não em termos econômicos (RK, 44).

10 Esse problema foi formulado de maneira precisa por Carlo Galli. Segundo ele, quando comparada com a "forma gloriosa" da Igreja e sua representação de uma realidade substancial, divina, a representação estatal revela toda a sua carência de fundamento e garantia, apresentando-se como uma representação de uma "idéia ausente de ordem", cf. GALLI, Carlo Genealogia della Politica, Bolonha, Il Mulino, 1996, cap. VI; "Presentazione" in SCHMITT, Carl -Cattolicesimo Romano e Forma Política, Milão, Giuffrè, 1986; "Mediazione e decisione" in Il Centauro, $\mathrm{n}^{\circ}$ 15, 1985; sobre esse ponto, ver também NICOLETTI, M. - op. cit., cap. VII.

11 Para a dupla direção da representação , cf. NICOLETTI, M. - op. cit, p. 243. 
Se o representante "deriva a sua dignidade do povo" não é porque ele a obtém do povo, mas por que ele, paradoxalmente, constitui o povo ao representar a sua própria unidade. A sua autoridade, por assim dizer, não vem "de baixo", mas "de cima" (von oben), do fato de que ele "personifica" essa idéia, tornando-a visível e presente no mundo das aparências. Por isso, Schmitt insiste na noção de que "apenas uma pessoa pode representar em um sentido eminente e, na verdade, (...) uma pessoa dotada de autoridade [autoritäre Person]" (RK, 36). Essa personificação é, para ele, um elemento central da constituição de uma forma política, ou, como se diz na Teoria da Constituição, de uma Staatsform, de uma forma de Estado. Através da "forma", observa Schmitt, se dá a "apresentação [Darstellung] da unidade política". Por isso, "em todo Estado, deve haver homens que possam dizer: l'Etat c'est nous" (VL, 207).

A natureza ideal e, simultaneamente, pessoal da representação implica não só a "independência" do representante, mas também a "afirmação de uma diferença hierárquica". Apersonificação de um "valor superior" (RK, 36), nos diz Schmitt, confere àquele que a realiza uma "dignidade particular" (RK, 36), de tal maneira que a pretensão de representar é, ao mesmo tempo, uma pretensão de autoridade (cf. RK, 45). A importância da representação no pensamento de Carl Schmitt é indissociável do pressuposto de que toda ordem política exige algum tipo de estruturação hierárquica, sem o que não haveria como estabelecer a diferença específica sobre a qual se baseia o próprio ato de governar. Em última análise, a crença em uma ordem fundada em si mesma seria a expressão mais radical e, ao mesmo tempo, mais conseqüente da imanência do pensamento técnico-econômico. A eliminação da atitude representativa do horizonte da experiência moderna teria como resultado extremo a eliminação do próprio governo e da política como dimensões necessárias da constituição de ordem na vida social.

$\mathrm{O}$ fato de que o representante desempenha esse papel de apresentação (Darstellung) é indissociável do reconhecimento da natureza eminentemente pública do ato de representar. Para Schmitt, não há representação que possa prescindir de algum tipo de visibilidade, já que essa última é a condição através da qual se produz uma "aparição [Erscheinung] concreta" (VL, 210) do ser representado. A idéia da unidade política de um povo se realiza a partir do momento em que vem a público, tornando-se visível e aparente por meio da ação pessoal do representante. Essa última, portanto, se dá sempre "on a public stage"12. A efetividade da representação política 
não dependeria, portanto, de uma autorização, mas sim do fato de que o público ao qual se dirige se reconhece como um todo na atuação do representante ${ }^{13}$. Essa dimensão pública estaria em clara oposição à "fundamentação liberal na esfera do privado" (RK, 49). Enquanto Schmitt associa a publicidade à atualização de um "todo", o privado é identificado à fragmentação em uma pluralidade de interesses. Para ele, o movimento de privatização característico da sociedade burguesa a teria tornado incapaz de uma autêntica atividade representativa ${ }^{14}$. $\mathrm{Na}$ ordem liberal, o princípio da representação se transformaria na idéia de uma representação-mandato, que Schmitt normalmente designa com as palavras Vertretung e Stellvertretung. Com isso, o significado público e formativo da Repräsentation cederia lugar a uma concepção eminentemente privada e a considerações técnicopráticas ou simplesmente econômicas. Nesse caso, o representante se colocaria em uma situação de dependência em relação à vontade do representado e a própria representação se veria reduzida a uma dimensão puramente funcional.

Para Schmitt, pelo contrário, a representação possui um sentido existencial. Esse é um ponto enfatizado na Teoria da Constituição. Segundo ele, "a representação pertence à esfera do político e, por isso, é na sua essência algo de existencial" (VL, 211) ${ }^{15}$. A aproximação entre a existencialidade do 'político' e a atividade representativa tem algumas implicações importantes. Em primeiro lugar, como sempre em Schmitt, essa dimensão existencial é definida em contraposição a um entendimento normativo da realidade política. Para ele, a natureza da representação não pode ser derivada de um sistema de normas, mas envolve a produção de publicidade. Se é verdade que a presença de uma unidade política é a condição de uma situação normal (cf. SpS, 159-160), por outro lado é preciso que ela seja visível para ser publicamente reconhecida. Sendo assim, a representação teria um papel decisivo na constituição de um quadro de normalidade capaz de assegurar a vigência de princípios normativos. Dessa maneira, Schmitt pode afirmar que

\footnotetext{
${ }_{13}$ Nesse sentido, Hasso Hofmann pode afirmar que, em Schmitt, a atividade do representante pode apenas ser confirmada (jamais autorizada) pelos representados, através da sua confiança e consenso (cf. op. cit., p. 184). De maneira semelhante, Giuseppe Duso afirma que a atividade representativa implica um elemento de confiança e de fé na unidade produzida (cf. $L a$ Rappresentanza: un problema di filosofia politica, p. 106).

${ }^{14}$ Sobre esse ponto, ver, além de RK, o prefácio à segunda edição de PR.

15 Em VL, essa insistência na dimensão existencial da representação implica uma atenuação do pólo institucional da análise de Schmitt, cf. DUSO, Giuseppe - op.cit., pp. 88 e 105.
} 
não se apreende a diferença entre o governo de uma coletividade ordenada e o poder [Macht] de um pirata através de concepções de justiça, utilidade social e outras normatividades, porque o ladrão também pode fazer jus a todas essas normatividades. A diferença reside no fato de que o autêntico governo 'representa' a unidade política de um povo e não o povo na sua existência natural [natürlichen Vorhandensein] (VL, 212; grifo do autor).

A natureza existencial da representação implica não só a sua autonomia em relação a considerações de caráter normativo, mas também a sua precedência. É preciso, pode-se supor pelo trecho acima, que a justiça e a utilidade social sejam reconhecidas como algo que diz respeito ao todo para que façam sentido como normas dotadas de validade geral. Schmitt, da mesma forma que Hobbes, considera que a definição de um espaço público é a condição de validade dos princípios normativos. Nesse sentido, é preciso estabelecer uma hierarquia entre os homens para que as normas possam ser concretamente interpretadas, aplicadas, mas também instituir algum tipo de visibilidade e publicidade que assegure o seu reconhecimento coletivo. Na verdade, as duas questões não se distinguem no pensamento de Schmitt, pois, como vimos, a representação é, a seu ver, inseparável da constituição de uma autoridade pública e, portanto, da diferença entre governantes e governados.

Por outro lado, a existencialidade da representação faz com que ela esteja referida à possibilidade extrema que distingue o "político", ou seja, o conflito. Como Hasso Hofmann bem reconheceu, se é verdade que a representação é sempre uma representação da idéia de unidade política de um povo, essa última, já sabemos, pode mobilizar os mais diferentes conteúdos. Dessa forma, é possível afirmar que, para Schmitt, "a representação é essencialmente luta pela representação"16. O estabelecimento de uma situação normal resulta da afirmação e da vitória de uma idéia de ordem sobre outras. O espaço público instituído pela representação e o "todo do povo" que se tornam presentes e visíveis por seu intermédio são o produto de um ato de exclusão, jamais a expressão de uma unidade contida em si mesma. A representação política, no sentido que a entende Schmitt, não pode ser a expressão de um modelo universalmente

${ }^{16}$ HOFMANN, Hasso - op. cit., p. 185. Como observa o próprio Schmitt em VL, "a luta pela representação é sempre uma luta pelo poder político" (VL, 212). 
válido de ordem; ela não exibe um fundamento próprio, mas é apenas a condição de uma forma substancial, cujo conteúdo preciso permanece indeterminado.

Idealidade, transcendência, caráter pessoal, hierarquia, publicidade, existencialidade estão vinculadas, na análise de Schmitt, ao princípio da representação, e se contrapõem à imagem de uma ordem "objetiva", imanente, impessoal, horizontal, privada; uma ordem, enfim, que conteria em si mesma o seu próprio princípio de totalização. Para ele, a representação não é um modo de dar expressão à vontade popular ou aos interesses sociais, mas sim uma maneira de constituir e formar a "unidade do todo [Ganzen]" (VL, 214). A sua importância na "condução normativa da vida social" está diretamente associada ao fato de que através dela algo de essencialmente informe, a realidade da vida política, assume uma forma própria. Aconfiguração de forma política implica, ao mesmo tempo, a constituição de identidade coletiva. A atividade representativa se apresenta em Schmitt como uma espécie de princípio de identificação que torna possível o reconhecimento público do caráter unitário da vida coletiva. A construção dessa identidade pressupõe uma estruturação vertical do espaço público. A diferença hierárquica sobre que se baseia a autoridade do representante é um fator constitutivo dos vínculos de dominação e subordinação que caracterizam a ordem política (cf. VL, 5). O espaço público, nessa perspectiva, se define como um universo de relações verticais, no qual, por meio de um duplo movimento de apresentação e reconhecimento, se configura uma totalidade, o "todo do povo", que transcende a experiência empírica. Por outro lado, ainda que a representação política não possua, no pensamento de Carl Schmitt, um fundamento normativo, ela é a condição de uma validação substantiva da existência política. A representação, ao tornar visível a idéia de unidade política de um povo, é um fator de produção de consenso e torna possível o reconhecimento público dos conteúdos e dos valores sobre os quais se funda a própria ordem.

O seu conceito de representação, no entanto, tem um caráter estritamente formal. Mesmo quando discute o papel normativo da representação política, Schmitt evita defini-lo em termos substantivos. Se o princípio da representação está associado à "condução normativa da vida social", isso não se deve ao fato de que ele garanta a realização de uma hierarquia de valores previamente dada. $\mathrm{Na}$ verdade, como se vê em 
Catolicismo Romano e Forma Política, esse papel normativo está associado fundamentalmente à conformação unitária da vida política, à criação de uma complexio. À semelhança do modelo eclesiástico, a representação estatal realiza uma mediação entre idéia e realidade, por meio da qual essa última adquire uma forma própria. Por outro lado, como insiste Schmitt em diferentes oportunidades, essa forma criada pela representação possui um caráter substancial. Em primeiro lugar, ela não se confunde com a natureza abstrata, contida em si mesma, auto-referente e fundada em dualismos das formas da razão técnico-econômica. A forma jurídico-política possui, segundo Schmitt, um caráter concreto, aberto à "matéria da vida humana" e capaz de configurar as suas contradições e a sua multiplicidade em uma unidade compreensiva. Ela tampouco se assemelha às formas vazias da objetividade, precisão e calculabilidade da técnica moderna. Mesmo não sendo derivada de um conteúdo normativo, a forma jurídico-política é substancial porque, em última análise, envolve na sua própria concretização a convicção compartilhada em torno de uma idéia substantiva de ordem.

$\mathrm{O}$ vínculo que Schmitt estabelece entre princípio representativo, forma jurídico-política e condução normativa da vida social me parece central para uma análise mais matizada do seu pensamento, uma análise que faça jus às suas ambivalências e ambigüidades. Seria um equívoco imaginar que a sua insistência na dimensão conflitiva da vida coletiva e na ausência de fundamento da ordem significa uma valorização unilateral dos elementos irracionais da existência social. Hugo Ball está correto quando afirma que um tema central do pensamento de Schmitt está na relação entre o racional e o irracional ${ }^{17}$. Não se trata, para Schmitt, de opor à "mitologia mecanicística e matemática" (RK, 33) ${ }^{18}$ da época moderna uma concepção igualmente dualista que recusa toda dimensão normativa em nome do primado da vida e da existência. Conceber a vida política nesses termos equivaleria a reduzi-la à sua dimensão puramente factual, recaindo, em alguma medida, na mesma Dinghaftigkeit do pensamento técnicoeconômico ou então na defesa de uma positividade não muito distinta daquela que o próprio Schmitt ataca no positivismo jurídico. O seu problema não está em afirmar os direitos do individual em face do universal, do

${ }^{17}$ Cf. BALL, Hugo. "La teologia politica di Carl Schmitt" (1924) in SCHMITT, Carl - Aurora Boreale. Nápoles, ESI, 1995.

18 A idéia de que a época moderna seria uma "época mecanicística" é um tema central da sua crítica à modernidade em RK e em um livro anterior, datado de 1916, Theodor Däublers "Nordlicht". Drei Studien über die Elemente, den Geist und die Aktualität des Werkes (em particular, cap. III). 
irracional frente ao racional, do poder perante o direito, da particularidade das relações de força diante da generalidade das normas jurídicas, mas sim de encontrar uma mediação entre esses termos. É nesse enquadramento conceitual que precisam ser interpretados os temas da decisão soberana e do conflito político em Carl Schmitt ${ }^{19}$.

Com efeito, a análise da soberania no pensamento de Schmitt está associada à afirmação da impossibilidade de conter o conjunto da experiência concreta no interior de uma ordem normativa; ou, o que dá no mesmo, à crítica da imagem do direito como uma realidade auto-suficiente. Ao se articular em torno dos eixos exceção e decisão, essa análise assume a necessidade do conflito e da violência como fatores de instauração da ordem e impõe o reconhecimento de um dado irracional originário que seria inerente a toda racionalidade normativa. Todavia, seria um engano reduzir o exercício da decisão soberana ao mero aspecto da força e ao puro e simples poder, como se soberania nada mais fosse do que uma espécie de memória do estado de natureza em plena ordem civil. Como o próprio Schmitt observa, "o poder [Macht] não prova nada para o direito". Nessa perspectiva, prossegue ele, "o vínculo entre o poder supremo de fato e o de direito é o problema fundamental do conceito de soberania" (PT, 26).

Ainda que não possa ser deduzida das normas jurídicas, a decisão soberana extrairia sua razão de ser de um vínculo com o direito e com uma idéia de racionalidade jurídica. Concebê-la exclusivamente como uma mera manifestação de força e poder significaria a anulação da sua qualidade especificamente jurídica; significaria, em última análise, renunciar à pretensão que tem o direito de governar a existência concreta. A decisão soberana se distinguiria de uma imposição arbitrária e ocasional pelo fato de criar as condições concretas da vigência do direito, introduzindo na situação a ser governada algum grau de previsibilidade e estabilidade. No nada normativo do estado de exceção, o estabelecimento de uma situação normal está associado à exclusão das decisões alternativas e, portanto, das possibilidades conflitantes de ordem. A constituição da normalidade implica a determinação de um sentido para o interesse público e, portanto, a conformação da realidade a partir de uma certa idéia de ordem. A decisão do soberano sobre o estado de exceção se define em relação à norma que ela própria exclui. Dito de outra maneira: a exceção é sempre

${ }^{19} \mathrm{O}$ que se segue deve em grande medida aos trabalhos já citados de Carlo Galli e Michele Nicoletti 
uma exceção em face de uma determinada idéia do direito. Na exceção, se demonstra, é verdade, a anterioridade e a independência da decisão em relação à norma, assim como a impossibilidade de conceber essa última como fundamento da ordem. Mas não só. Também torna-se evidente, insisto, o vínculo entre a decisão e uma idéia de ordem normativa. Faz parte da própria natureza da decisão soberana o paradoxo que, segundo Schmitt, seria característico da ditadura, ou seja, ela "ignora o direito (...) para realizá-lo" (D, XVIII).

Essa "realização do direito" implica, portanto, uma configuração da vida social segundo determinados parâmetros de normalidade, em virtude dos quais a realidade concreta ganha uma forma própria e as relações entre os homens podem ser submetidas a regras comuns. A transposição do direito na realidade envolve uma tensão entre a idéia de ordem e a natureza contingente e indeterminada da situação concreta à qual ela se aplica. Ao instaurar uma situação normal a partir do caso de exceção, a decisão soberana, na verdade, concretiza uma idéia de normalidade; ela realiza, em última análise, uma mediação entre o dever-ser do direito e o ser da realidade. Assim, em contraste com a noção de uma normalidade de princípio implícita nos dualismos da época moderna - ou seja, em contraste com a convicção de que o direito, a moralidade, as leis da razão, as normas da técnica são válidas em todas as circunstâncias -, Schmitt recorre a uma outra polaridade. Uma polaridade que, segundo ele, "retira desses conceitos a capacidade de se contraporem ao 'poder' [Macht] sob a forma de oposições sumárias" 20 . Trata-se, enfim, da "oposição fundamental" 21 entre normalidade e exceção. Para ele, essa traz para frente de cena o quis judicabit? de uma decisão pessoal, que se apresenta não só como o fundamento de validade de uma ordem normativa, mas também como instância de mediação entre essa última e a realidade. Nesse sentido, o decisionismo de Schmitt representa uma tentativa de pensar uma conformação da existência política que, sem abolir a tensão entre norma abstrata e realidade concreta, evite a sua exclusão recíproca.

Nessa perspectiva, Schmitt pode dizer, em Teologia Política, que a discussão sobre a soberania está associada ao "problema do direito como uma forma substancial" (PT, 31). O caráter substancial que se reivindica aqui para a forma jurídica tem como premissa essa configuração da

20 "Zu Friedrich Meineckes Idee der Staatsräson" (1926) in PuB, 57.

${ }^{21}$ Id., 53. 
experiência concreta a que me referi há pouco; ou ainda, para empregar os termos do livro sobre o catolicismo, um movimento de conformação da "matéria da vida humana", através do qual essa última ganha ordem e unidade concretas. Ele pressupõe, por assim dizer, uma resolução, ainda que particular e localizada, da tensão entre dois planos cuja correspondência jamais é imediata: o plano da norma e o da realidade social. A decisão cumpriria o papel de mediação entre esses dois níveis, contendo em si, nas palavras de Schmitt, "um elemento constitutivo, um valor específico [Eigenwert] da forma" (PT, 33). Esse valor, por sua vez, seria indissociável de um "momento personalístico" (PT, 38). Por oposição à imagem de uma norma objetiva, impessoal e universalmente válida, característica das concepções do Estado de direito no liberalismo, Schmitt afirma a necessidade de uma instância última de decisão pessoal, capaz de determinar as condições de validade de uma ordem normativa. Como essas condições não podem ser estabelecidas normativamente, a transposição de um princípio jurídico na realidade nunca é uma mera derivação de um conteúdo. Ela traz consigo o conflito e a necessidade de definição de uma instância competente, um sujeito politicamente constituído que assuma a responsabilidade da decisão pessoal.

Não acredito que seja necessário me estender ainda mais sobre esse ponto para que fique clara a afinidade entre os conceitos de representação e soberania no pensamento de Carl Schmitt. Em ambos os casos, a constituição da ordem aparece como o resultado de uma mediação pessoal entre a indeterminação concreta das relações políticas e a abstração transcendente da idéia de unidade ${ }^{22}$. Nesse sentido, decisão e representação desempenham na reflexão de Schmitt um papel central: elas lhe permitem pensar a ordem jurídico-política como algo que necessariamente transcende o caráter imediato e contingente da existência política, mas que, ao mesmo tempo, extrai a sua força da capacidade de criar a partir dessa contingência uma concepção unitária. A afirmação do político no pensamento de Carl Schmitt envolve, portanto, um duplo movimento: ela traz para o primeiro plano um elemento transcendente característico da constituição da ordem política e, ao mesmo tempo, afirma a impossibilidade de que essa última contenha em si mesma o seu próprio fundamento. Paradoxalmente, ao sublinhar esse traço ideal, Schmitt põe em evidência a natureza confli-

22 Giuseppe Duso (La Rappresentanza) e Michele Nicoletti (Trascendenza e potere) insistem nesse elemento de mediação da decisão soberana. 
tiva da forma política. Não por acaso, ele se permite falar na Teoria da Constituição, do "representante que decide [dem entscheidenden Repräsentanten]” (VL, 56). Carlo Galli sintetizou de forma precisa esse ponto ao afirmar que, em Schmitt, a ação política significativa envolve uma "decisão pela representação", na qual entre desordem e ordem, exceção e excesso se apresentam co-implicadas ${ }^{23}$.

Não quero, com isso, dizer que decisão e representação sejam equivalentes entre si. Pretendo, isso sim, sublinhar que a imagem da decisão soberana como um ato que "cria e garante a situação como um todo na sua totalidade [als Ganzen in ihrer Totalität]" (PT, 19) implica um movimento de formação e configuração da existência política e traz consigo um componente ineliminável de representação. Por outro lado, também é preciso reconhecer que a representação como um ato de "apresentação [Darstellung] da unidade do todo" (VL, 214) jamais é a concretização pacífica de uma idéia de ordem consensualmente aceita, mas requer um ato de exclusão, um momento de decisão sem o qual a idéia de unidade não se torna presente. Se é possível falar em princípio transcendente da ordem política, essa transcendência jamais se apresenta como a expressão de um fundamento substantivo, mas, paradoxalmente, como a condição formal daquilo que se apresenta como "o conceito decisivo, ou seja, o da forma em um sentido substancial" (PT, 33)24.

Nesse sentido, parece-me que Giuseppe Duso tem razão quando observa que, em Schmitt, a configuração política do mundo é indissociável de uma "estrutura radical de implicação da transcendência" 25. A ordem política jamais pode ser um produto imediato da existência em sociedade, pois essa é, em si mesma, informe e cindida por contradições. Seria preciso transcender a sua indeterminação concreta e, a partir de uma idéia específica de ordem, lhe conferir forma e unidade. A ordem não pode jamais ser reduzida a um simples fato, a algo que, no seu mutismo moral, se "justificaria" por si mesmo, pela mera capacidade de se fazer presente no mundo das coisas. A necessidade de justificação e validação

${ }^{23}$ Esse é um dos eixos da sua interpretação de Carl Schmitt no já citado Genealogia della Politica. Para Galli, soberania e representação se apresentam como os dois lados a partir dos quais Schmitt pensaria a natureza originária da política: por um lado, a exceção, como ausência de ordem; do outro a idéia, como um excesso que compele à ordem.

${ }^{24}$ Para a idéia de "transcendência formal", permito-me remeter ao meu texto: FERREIRA, Bernardo - Tragédia e destino: Friedrich Meinecke e Carl Schmitt, mimeo., 1996.

25 DUSO, Giuseppe - La Rappresentanza, p. 119. 
da ordem colocaria a exigência de remetê-la para além de si mesma, para algo de ulterior ${ }^{26}$.

Todavia, essa "implicação da transcendência" não é nunca a tradução incontroversa e pacífica de um modelo ideal na realidade; o ideal, longe de se situar acima do real, apresenta-se, em Schmitt, atravessado pelos antagonismos inerentes a este último. Uma vez mais, a técnica moderna se apresentaria como a expressão extrema de uma concepção puramente secular da ordem: ela não só anularia essa dimensão transcendente na objetividade de processos coisificados, como também partiria da premissa de uma normalidade fundada na sua própria imanência, uma normalidade em que as coisas se governariam por si mesmas e o conflito seria eliminado do horizonte da vida social. Aos olhos de Schmitt, a modernidade técnico-econômica neutralizaria o problema do político em uma concepção em que a ordem se veria reduzida ao produto automático de uma legalidade imanente e o governo dos homens substituído pela administração das coisas.

Sendo assim, o reconhecimento da natureza existencial do conflito político, da impossibilidade de deduzi-lo de critérios substantivos não é contraditória com o fato de que a decisão sobre o inimigo implica uma decisão por uma idéia de ordem. É certo, como observa Hasso Hofmann, que essa idéia "não é mais um problema de conhecimento, mas o produto de uma decisão externa" 27 . Todavia, o reconhecimento da ausência de fundamento normativo da decisão não é o mesmo que a eliminação da dimensão normativa. Para Schmitt, essa dimensão tem um papel central na consideração do antagonismo político, o qual gira necessariamente em torno de determinados conteúdos substantivos. Mas não só. A sua análise do "político" tem um caráter não apenas descritivo, mas também, por assim dizer, prescritivo: a inimizade política é, a seus olhos, a condição de uma estruturação substancial da ordem e de uma condução normativa da vida social. Ela define não apenas os termos do dissenso entre os homens mas também

26 Tomo emprestada a idéia de "ulterioridade" de Michele Nicoletti, que a emprega em um contexto um pouco diferente para caracterizar a concepção que Schmitt tem do direito, cf. Trascendenza e potere, pp. 140-142. Não por acidente, tanto na análise do romantismo quanto na discussão do pensamento técnico-econômico, a anulação da transcendência vem acompanhada de um movimento de privatização. A estetização generalizada promovida pelo sujeito romântico representaria uma forma de privatização de todas as esferas da experiência, dissolvendo todo e qualquer princípio de ordem pública. A hegemonia do pensamento técnicoeconômico, igualmente, seria indissociável de uma preeminência dos vínculos de direito privado e de uma limitação da natureza pública da forma jurídica.

${ }^{27}$ HOFMANN, Hasso - op. cit., p. 110. 
as condições de um consenso; não apenas os fatores de dissociação, mas também a possibilidade de associação. A pergunta pela natureza do "político" traz consigo o problema da afirmação de uma identidade coletiva de caráter substantivo. Aconstrução dessa identidade política envolve necessariamente um elemento ideal, ela pressupõe a atualização e a concretização de uma idéia de ordem e de unidade, sem o que "o todo do povo" não se faz presente e visível. Nesse sentido, a discussão do "político" em Schmitt está estreitamente ligada à questão da forma política e, por conseguinte, à temática da representação. A associação política em Schmitt é, como disse há pouco, uma associação por dissociação, mas também, se os termos me são permitidos, uma associação por representação. A constituição da unidade política tem como premissa uma estruturação vertical e representativa do espaço público, por intermédio da qual se realiza a "apresentação da unidade do todo". O antagonismo político, na medida em que pode ser concebido como um fator de integração, encontra a sua contraface na constituição de uma hierarquia entre homens e instâncias concretas, através da qual os valores da vida coletiva venham a ser publicamente reconhecidos. Essas considerações permitem iluminar um trecho significativo de Catolicismo Romano e Forma Política:

nenhum sistema político pode sobreviver, mesmo por uma geração, através da mera técnica de manutenção do poder [Machtbehauptung]. A idéia faz parte do político [zum Politischen gehört die Idee], porque não existe política sem autoridade e não há autoridade sem um ethos da convicção [Ethos der Überzeugung] (RK, 28).

Em 1923, quando foi publicado Catolicismo Romano e Forma Política, Schmitt ainda não havia elaborado a sua análise sobre o "conceito do político", muito embora, até onde vejo, o uso do substantivo das Politische já se verifique desde a primeira edição de Teologia Política, em $1922^{28}$. Mesmo assim, não me parece que essa associação um tanto

28 A primeira edição de Der Begriff des Politischen é de 1927. Segundo Piet Tomissen, Schmitt teria elaborado a sua análise do "político" em seminários na Universidade de Bonn nos anos de 1925 e 1926. (Cf. TOMISSEN, Piet. "Contribuitions de Carl Schmitt a la Polémologie" in Revue Européenne des Sciences Sociales (número especial dedicado a Carl Schmitt - "Miroir de Carl Schmitt"), tomo XVI, n 44, 1978, p. 146. Em PT, o uso do substantivo das Politische comparece em um trecho há pouco citado, em que Schmitt afirma que "não há nada mais moderno hoje do que a luta contra o político" (PT, 68). 
enigmática entre "político" e idéia tenha sido abandonada na sua reflexão subseqüente. Pelo contrário, penso que ela se torna ainda mais clara se a considerarmos à luz da relação que posteriormente Schmitt irá estabelecer entre "político" e intensidade em O Conceito do Político. Para ele, as contraposições entre os grupos humanos ganham um significado especificamente político quando se aproximam do grau de intensidade extremo da dissociação entre amigos e inimigos. Esse grau de intensidade pode ser atingido a partir das mais diferentes esferas da experiência humana, sem que o "político" venha a ser definido por qualquer uma delas. O "político", portanto, não possui um conteúdo próprio, embora possa recobrir os mais diferentes tipos de conteúdos. Para Schmitt, o que faz com que uma certa esfera da experiência se veja revestida de um significado político não é algo já contido nela mesma, mas o fato de que "os conflitos e as perguntas decisivas se dirijam para essa esfera" (HV, 111); ou seja, é preciso que o antagonismo em torno de determinados problemas substantivos divida os homens em amigos e inimigos. Nesse momento extremo em que o "ponto do político" (BP, 62) ${ }^{29}$ é alcançado, os conteúdos específicos dos antagonismos em jogo "se tornam a nova substância da unidade política" (BP, 39). Com uma diferença fundamental, "uma intensidade qualitativamente nova do agrupamento humano é alcançada" (BP, 62; grifo do autor). Nesse momento, nos diz Schmitt,

a oposição não-política (...) põe de lado os seus critérios até então 'puramente' religiosos, 'puramente' econômicos, 'puramente' culturais e se submete às condições e conseqüências totalmente novas e particulares da situação daqui em diante política, condições e conseqüências essas que, consideradas daquele ponto de partida 'puramente' religioso ou 'puramente' econômico e de outra perspectiva 'pura' qualquer, se apresentam muito freqüentemente como inconseqüentes e 'irracionais' (BP, 39).

À idéia de que a contraposição política é "a mais intensa e extrema" (BP, 30) corresponde a qualificação, em Schmitt, da unidade política como maßgebende ("que dá a medida"), höchste ("suprema"), bes timmende ("determinante"), intensivste ("a mais intensa") Einheit;

${ }^{29}$ Para idéia de "ponto do político", ver também SpS, 160. 
expressões que apontam para a sua superioridade em relação a todo outro tipo de comunidade humana ${ }^{30}$. No pensamento de Schmitt, essa superioridade está estreitamente associada à diferença qualitativa que caracteriza o grau de intensidade do agrupamento político. Para Schmitt, semelhante superioridade e diferença qualitativa, ainda que inseparáveis do grau de intensidade de um conflito existencial, não são simplesmente dados tangíveis ou, como ele afirma em Teoria da Constituição ecoando certas concepções do livro sobre o catolicismo, não se trata de algo "realmente presente [gegenwärtig]" (VL, 210), mas, em última análise, de uma idéia. Essa qualidade superior da unidade política está associada à formação de uma identidade específica, a identidade política, que, por definição, transcenderia o caráter imediato da vida coletiva. Ela implicaria um movimento de integração por meio do qual um todo, "o todo do povo", se formaria a partir da matéria informe da vida social; envolveria, portanto, uma configuração substantiva da natureza múltipla e contraditória da existência social a partir de uma idéia igualmente substantiva de unidade. Nesse sentido, a intensidade característica do antagonismo político conteria em si um componente ineliminável de representação. Se a inimizade política é um fator de produção de unidade, essa, por sua vez, não se reduziria a um simples dado da experiência empírica. Como nos diz Schmitt na Teoria da Constituição,

na representação, adquire aparência concreta uma espécie mais alta de ser. A idéia da representação se baseia no fato de que um povo que existe como unidade política possui [als politische Einheit existierendes Volk] uma espécie de ser mais alta e elevada, mais intensa [höhere, gesteigerte, intensivere] em face da existência [Dasein] natural de qualquer grupo humano que viva em comum. Quando desaparece o sentido dessa particularidade da existência política [politischen Existenz] e os homens preferem outros gêneros da sua existência [Dasein], também desaparece a compreensão de um conceito como o de representação (VL, 210; grifo meu).

30 A título de exemplo: "maßgebende Einheit" (BP, 39), "höchste Einheit̂̂" (BP, 43 e SpS, 160), "bestimmende Einheit" (BP, 43), "intensivste Einheit" (SpS, 160). Para a idéia da superioridade da unidade política sobre todos os outros tipos de comunidade humanas, cf. BP, 48 e SpS, 160. Segundo Schmitt, essa superioridade está associada à capacidade da unidade política de decidir sobre o "caso crítico" e de exigir, se for necessário, o sacrifício da vida dos seus membros. 
A natureza conflitiva do "político" está, portanto, diretamente associada a um momento ideal em pelo menos dois aspectos. Primeiramente, como observei há pouco, o conflito político se dá sempre em torno de questões substantivas, ele implica uma contraposição entre idéias antagônicas de ordem. Em segundo lugar, o grau de intensidade característico do agrupamento amigo-inimigo traz consigo a idéia de uma unidade superior que não é algo de tangível e não se dá de maneira imediata.

Em Schmitt, portanto, a constituição da unidade política não é concebível sem o componente de alteridade que seria característico da existência de uma autoridade pública ${ }^{31}$. Não nos esqueçamos, a forma política pressupõe uma representação von oben ("de cima para baixo") e a concretização da idéia de ordem política em uma "pessoa dotada de autoridade". Nesse sentido, a imagem de uma "associação por representação" envolve uma estruturação literalmente autoritária do espaço público como a condição de vigência da ordem. Aqui, a objetivação da ordem em um outro, em uma autoridade pública, parece ser a premissa do seu reconhecimento coletivo. Nesse sentido, a constituição de uma autoridade pública envolve não só o par proteção-obediência, mas também o binômio repre sentação-reconhecimento ${ }^{32}$. Esse reconhecimento não é concebido como o resultado da correspondência entre ação de um mandatário e as expectativas dos seus mandantes, pois, já sabemos, a representação aqui não é concebida em termos do mandato. Ele está associado à idéia de que os representados reconhecem a sua própria unidade na medida em que ela é personificada pela ação do representante. Nesse sentido, penso que o problema do "ethos da convicção" a que Schmitt se refere no trecho há pouco citado reside menos no conteúdo normativo dos valores e princípios sobre os quais se funda a autoridade, do que na possibilidade da sua vigência efetiva como valores e princípios coletivos. Tentando ser um pouco mais claro a respeito desse ponto: trata-se, para ele, de pensar as condições de um consenso em torno de questões substantivas, em um quadro em que não é possível deduzir a ordem de conteúdos normativos pressupostos e univer-

${ }^{31}$ Para esse componente de alteridade, vejam-se as observações de Giuseppe Duso em "Tra costituzione e decisione: la soggettività in Carl Schmitt" in - La Politica oltre lo Stato: Carl Schmitt, Veneza, Arsenale, 1981, em particular pp. 57-58.

32 Segundo Schmitt, "protego ergo obligo é o cogito ergo sum do Estado" (BP, 53). A referência aqui, como o próprio Schmitt reconhece, é Thomas Hobbes. A aproximação com Hobbes, a meu ver, pode ser estendida ao que disse nesse parágrafo sobre o tema da representação. 
salmente reconhecidos ${ }^{33}$. Dessa forma, se é verdade, por um lado, que a consolidação de uma autoridade pública pressupõe um "ethos da convicção", por outro, não há convicção que se sustente sem um "pathos da autoridade" (RK, 31) que lhe confira um caráter público e visível. Para Schmitt, pode-se afirmar, não há ordem que não se funda sobre determinados princípios e valores, contudo, por mais paradoxal que possa parecer, a efetividade e validade desses últimos é indissociável do reconhecimento coletivo da própria ordem.

BERNARDO FERREIRA é professor visitante do Departamento de Ciências Sociais da Universidade Estadual do Rio de Janeiro.

${ }^{33}$ Como observam Eric Voegelin (cf. VOEGELIN, Eric - "La Dottrina della Costituzione de Carl Schmitt. Tentativo di analisi costruttiva dei suoi principi teorico-politici" (1931) in DUSO, Giuseppe (org.) - Filosofia Politica e pratica del Pensiero, Milão, Franco Angeli, 1988, p. 297) e Hasso Hofmann (cf. op. cit., p. 121), sob determinados aspectos, Schmitt retoma a concepção de Max Weber a respeito da validade empírica dos princípios normativos. Da mesma forma que Weber, ele distinguiria o conteúdo de verdade dos valores da sua efetividade prática na vida social e tenderia a enfatizar a segunda em relação ao primeiro. Essa avaliação me parece essencialmente correta, mas ao mesmo tempo considero necessário sublinhar as conclusões de natureza normativa que Schmitt extrai dessa distinção. Ao insistir na impossibilidade de uma fundamentação da ordem em uma norma pressuposta e universalmente reconhecida, ele não restringe a reflexão jurídico-política a uma perspectiva puramente empírica e descritiva do direito e da política como fenômenos sociais. Ainda que se sirva amplamente de material histórico e sociológico, Schmitt não é, digamos, um "cientista social". Se é verdade que ele assume a distinção de Max Weber entre a validade empírica e a validade normativa dos juízos de valor, o seu problema continua a ser o das condições de possibilidade de uma ordem normativa. Não raro, os seus textos exibem uma desorientadora combinação de sensibilidade empírica, "realismo" e postura prescritiva. Paradoxalmente, a sua recusa da possibilidade de uma fundamentação normativa da vida política não tem um significado puramente descritivo, mas, na verdade, normativo. 